\title{
Compliance of small-scale Organic Tea Farmers with Organic Standards: A Study in Sri Lanka
}

\author{
S. M. C. B. Karalliyadda ${ }^{1,2^{*}}$ and T. Kazunari ${ }^{3}$ \\ Received: 20 $0^{\text {th }}$ July 2019 / Accepted: $10^{\text {th }}$ September 2019
}

\begin{abstract}
Purpose: Authenticity of organic tea has been questioned recently due to some evidence of contaminated organic tea in the market. Although producers' compliance with organic standards (OS) is a necessity to ensure the safety of organic tea and consumers' trust, the lack of empirical studies has become a timely need to understand the authenticity of organic tea production systems. Therefore, this study attempts to investigate the certified organic tea (COT) farmers' compliance behaviour with OS using a study in Sri Lanka.
\end{abstract}

Research Method: A cross-sectional field survey was conducted among 77 small-scale COT farmers in the Central and Uva provinces. These farmers were accessed through two coordinating organizations. Data was collected using interviews, structured questionnaires and observations and analyzed using descriptive statistics.

Findings: Results show that higher profits and benefits from certificate holders are the main reasons to select COT farming than conventional tea farming. Generally, farmers perceive high discouragement violating OS and have mixed attitudes on different aspects of organic farming. Farmers' compliance behaviour towards $O S$ is not perfect and vary among OS due to various reasons, i.e. expected loss by being noncompliant, group farming, availability of support services, financial ability and awareness about hazardous contaminants. Effective quality assurance system and hazardous free neighbourhood potentially facilitate the farmers' compliance behaviour. However, the unavailability of support services, lack of financial capacities, and farmers' unawareness of contaminants during handling seem to hinder the compliance.

Originality: Understanding the first step of COT production is novel and provide insights to implement needful actions by those who are concerned and responsible for the authenticity of COT production.

Keywords: certified organic tea, tea farmers, small-scale, compliance

\section{INTRODUCTION}

Today's consumers are more health-conscious and highly concerned about the safety of the products that they consume. Their knowledge, health consciousness and the attitude towards organic food lead them to purchase organic food (Hsu et al., 2016). Consumers are now closely looking at the information and labels attached to the products, to verify their safety. Organic food consumers focus on organic certification logos as an indicator of the authenticity of the organic product. However, there are questions about the authenticity of organic products despite the certifications provided by thirdparty certification agencies such as to what extent farmers obey the organic standards (OS), whether farmers have knowingly or

The United Graduate School of Agricultural Sciences, Kagoshima University, Kagoshima, Japan.

2* Faculty of Agriculture, Rajarata University of Sri Lanka, Anuradhapura, Sri Lanka.

chinthbk@gmail.com

3. Faculty of Agriculture, Saga University, Saga, Japan.

(iD https://orcid.org/0000-0002-6209-4722 
unknowingly disobeyed the OS and if so, will these acts be caught by the controlling systems. Answers to these questions are critical as they affect the trust in organic products. Violating the consumers' expectations and being noncompliant with OS, some organic products are found to be contaminated with pesticide residues (Tiriyaki, 2017; Cressy et al., 2009). Studies which have undertaken by some researchers reported that such kind of non-compliances occur if farmers have; less experience in organic agriculture, large farms, conversion area, previous non-compliance, processing activities, and diverse livestock (Zorn et al., 2013; Gambelli et al., 2014).

Similarly, perceived high cost for compliance, uncompetitive farm gate prices and low farm yield, and the presence of off-farm income are also identified as the reasons behind the noncompliance of other food-related standards (Muriithi, M and Ngigi, 2011). However, noncompliances with OS are not always intentional violations. Sometimes such non-compliances can be due to obstinate environmental contaminants (Tiriyaki, 2017). Therefore, investigating farmers' compliance behaviour with sufficient evidence from their field of operations is necessary to apprehend the reality behind their compliance behaviour.

Tea, as the world's most popular beverage after the water, is becoming more organic due to the influence of health concerns and the resultant food habits of tea consumers. The demand for certified organic tea (COT) is increasing at a higher rate while expanding its market potentials. However, recent evidence has uncovered that some of the organic tea products are contaminated with pesticides (Simpson 2009; Campbell, 2015; The Local 2017; Keen 2018). Surprisingly, in many countries, some of these pesticides (E.g., Endosulfan) are banned from using. (Campbell, 2015). Keen (2018) cited that farming practices of neighbouring farms, water run-off, pollution, poor soil management and poor hygienic conditions as possible reasons behind such contaminants. However, if the reality behind such non- compliances is not revealed, consumers may suspect that it is due to farmers' intentional or unintentional non-compliance, adulterations in processing, or inefficiencies of quality control systems. Therefore, a lack of knowledge on the COT production process may lose its consumers because of less assurance on the authenticity of COT products.

Sri Lanka, a pioneer in both production and exportation of tea in the world, has an increasing growth in COT farming and its exports. Sri Lanka mainly exports COT to the European Union countries, USA, Canada, Australia, Singapore and Japan (Vidanapathirana and Wijesooriya, 2014) and its revenue reduces the foreign trade deficits and provides socio-economic benefits for rural farmers (Gunarathne, 2015; Qiao et al., 2016;). Some of the Sri Lankan tea export consignments have been rejected and warned by importing countries due to quality-related issues (Lei, 2017; Dias, 2018). These rejections are challenges to maintain the goodwill of Sri Lankan tea and its economic benefits. Thus, the production of high-quality tea is always a necessity with regard to all tea products.

There are many small-scale organic food producers in the world, including organic tea producers. Majority of them are coming from developing countries such as India, Uganda and Mexico. Many local, international, private and government institutes are working hard to maintain the producers' compliance with OS and to assure the quality of final products. However, the evidence has shown that there has not been a systematic investigation of the production of COT to the date. This knowledge gap can slow down the necessary actions to avoid the bottlenecks of the development of the COT sector. Therefore, it is necessary to recognize how farmers are operating in the field level to identify challenges for compliances by then to design suitable strategies to overcome them.

\section{Why farmers comply?}

Compliance is extensively studied in various disciplines as non-compliance can result in 
severe consequences. The alternative words for compliance (E.g., adherence, co-operation, mutuality and the therapeutic alliance) make it challenging to bring compliance-related studies into a common understanding (Kyngäs et al., 2000). However, Kelman (1958) distinguishes the compliance as a type of conformity and explains it as a situation of accepting an influence by an individual as he/she thinks it will lead to receiving a favourable reaction from the influencer. According to Cialdini and Goldstein (2004), compliance is a kind of response to a request, either explicit or implicit.

There are many theoretical backgrounds which have been used to explain the compliance behaviour of farmers. Some of them include expected utility theory, prospect theory, psychological literature, sociological literature and institutional aspects while some others consider deterrence and contextual aspects (Herzfeld and Jongeneel, 2012; RamcilovicSuominen and Hansen, 2012; RamcilovicSuominen and Epstein, 2015). Expected utility theory explains how a person's decision is affected by the expected utility of uncertain outcomes of a decision. As an example, if the attainment of high income from organic farming has a high probability, the expected utility of organic farming will be high for farmers. Therefore, farmers adopt organic farming and comply with the OS to make their expected utility a reality. However, the utility of organic farming is subjective in the real context and not be solely on economic aspects but include other aspects like the development of farm operations (E.g., ability to control pests and weeds, development of the yield etc.) (Best, 2009). Therefore, a farmer's expected utility of organic farming may include both economic and non-economic aspects.

Deterrence literature explains peoples' obedience or violent behaviour on laws after calculating the gains and consequences of such behaviours. Deterrence is associated with punishments. When punishments are severe, certain, and swift for violation of a law, it will deter a rational person violating the law if the calculated loss is greater than the gain (Bosworth, 2005). RamcilovicSuominen and Hansen (2012) identified that people avoid felling trees in the forest as they fear of sanctions of forest rules. In certified organic farming, quality assurance systems are responsible for conducting field inspections and maintaining farmers' compliance with OS. Therefore, deterrence of violating OS reflects the effectiveness and efficiency of quality assurance systems.

Psychological literature emphasises the importance of attitudes and personal moral beliefs on compliance behaviour. Attitude is a feeling towards something or someone; behaviour is a way of expressing the attitude. Therefore, the nature of the attitude has a potential influence on compliance behaviour. In conservation studies, attitude on sustainability positively influence people to act against illegal anti-ecological behaviour (Martin et al., 2014).

Social influences are recognized as determinants of compliance in sociological studies. The normative and informative influences are the two distinct categories of these social influences. Normative influences are the influences to conform with the expectations of others (E.g., social norms) whereas informative influences (social proof) are the influences to accept information from others as evidence about reality (Deutsch and Gerard, 1955). According to social impact theory by Latane (1981), the social influence is a multiplicative function of strength (importance or power of the source), immediacy (closeness or the absence of barriers), and the number of influential sources (No of people). Sutinen and Kuperan (1999) cited that, social influence as an extrinsic motivation of compliance behaviour. Becker and Maiman (1975) cited social factors (E.g., doctor-patient relationship) as determinants of compliance with health and medical care recommendations. Sinnasamy, Bidin, and Ismail (2015) indicated that peer influence has a direct influence on compliance towards paying excise tax. Therefore, when COT farmers are under social influences (E.g., group farming), 
there will be an influence over their compliance behaviour.

Some studies cited institutional aspects as determinants of compliance behaviour. Tyler (2006) explains that people's compliance with the law is not a result of fear of punishment but a sense of the legitimacy of the institutions. Ramcilovic-Suominen and Hansen (2012) cited that people comply when they feel the rules are fair and important. Therefore, if COT farmers perceive OS are fairly developed for them, they may highly comply with it.

Contextual factors represent the background conditions forcompliance, such as the availability of supportive services, socioeconomic factors, and farm characteristics that can affect farmers' compliance behaviour. The study by Lippert and others (2014) found that organic farmers who have processing activities and high livestock diversity on the farm and past non-compliance are more non-compliant on OS. Zanoli and others (2012) found that farm characteristics (i.e. availability of nut production) are a possible cause of non-compliance among organic farmers in Turkey, while Gambelli and others (2011) identified that path dependence (presence of previous non-compliances) and co-dependency of non-compliance, farm size, complexity of crop production and availability of livestock as factors that can increase the probability of non-compliance towards OS. Zorn and others (2013) identified that less experience in organic agriculture, farm size, and the existence of a conversion area increase the probability of noncompliance.

In this paper, it has been attempted to investigate COT farming emphasizing the farmers' compliance with OS using a study in Sri Lanka. The specific objectives of the study are as follows; to investigate the background characteristics of COT farmers and their farming practices and farmers' compliance with different OS.

\section{MATERIALS AND METHODS}

The research design of this study was a crosssectional survey as it can generate a large amount of data in compliance-related studies (Arias, 2015). Compliance-related studies have a sensitive nature and a possibility of noncompliers to withhold their participation or to provide misleading answers. Therefore, the mixed method technique was also included to minimize the biases and to elaborate findings (Brannen, 2005).

It has estimated that the number of small-scale organic producers in Sri Lanka is nearly 20000, which is the $4^{\text {th }}$ largest in Asia (Meinshausen et al.,2019). These producers are generally joined to a processor or trader (Coordinator). However, there was no registry of COT farmers in Sri Lanka. Thus, a request was made to the coordinators of small-scale COT farmers (E.g., exporters, processors, and farmer organizations) to link COT farmers. This list is available in the study conducted by Vidanapathirana and Wijesooriya, 2014. These coordinators were the certificate holders of COT farmers, as their certificates of conformity are registered under these coordinators. Two certificate holders agreed to link their registered COT farmers for the study. One of them was a leading organic tea exporter while the other was from a farmers' association which owns the largest network of small-scale organic food producers. The smallscale COT farmers of these two certificate holders were in two provinces of Sri Lanka, i.e. Central and Uva. Thus, these locations were considered as the research sites of the study. The COT farmers belong to small groups are linked with each other to form farmer organizations. The total small-scale organic producers belong to both companies was 5607, of which nearly $60 \%$ of them were COT farmers. Due to difficulties of finding them in the field, the research team was escorted to meet farmers by the field officers. In the field, 77 small-scale COT farmers were selected based on their availability. 
Primary data was collected using interviews and structured questionnaires. The questionnaire was pretested using a pilot study and adjusted to match with the local language (Sinhala) and the context. The responses to all statements were measured in five-point Likert scales, which $1=$ lowest value and $5=$ highest value. Independent enumerators who were technically knowledgeable of organic farming were employed in data collection to minimize the biases of the respondents' answers. The importance of the truthfulness of the data was communicated to respondents in each data collection session to minimize the ambiguity of the questions and the purpose of data collection. Data collection was supplemented with the key informant and focus group discussion sessions with different stakeholders including government officials, field inspectors of thirdparty certification bodies, field inspectors of internal control systems, and leaders of farmer groups and farmers. Field observations were also conducted in each data collecting session to triangulate the data collected in the questionnaire survey and interviews. Enumerators were advised to observe COT farms with approval from the respondents. Confidentiality and the anonymity of the respondents were maintained; their information was not revealed to any party and respondents were not given any piece of advice to change the current farm practices.

The requirements of organic crop production cited in the "IFOAM NORMS for organic production and processing; version 2014" published by International Federation of Organic Agricultural Movement was considered as representative OS to measure the compliance of COT farmers. In that, these requirements are categorized into ten specific areas as below.

1. Split production and parallel production

2. Maintenance of organic management

3. Choice of crop and varieties and propagation of planting materials

4. Conversion period
5. Diversity in crop production

6. Soil fertility and fertilization

7. Pest, disease and weed management

8. Avoidance of contamination

9. Protected cropping

10. Breeding of organic varieties

However, four categories (i.e. Maintenance of organic management, conversion period, protected cropping, and breeding of organic varieties) were excluded as they were not applicable to these COT farmers. Finally, based on six requirements, 15 behavioural statements were designed to measure the COT farmers compliance towards OS. Descriptive statistics were used to analyse the data while providing simple summaries of data and their distributions.

\section{RESULTS}

\section{The socioeconomic characteristics of COT farmers}

According to Table 01, many respondents were elderly farmers. Both male and female farmers were nearly in equal proportions. Women's participation was high due to the presence of less heavy work in regular farm practices and the proximity of the farmland to the house. Many farmers had more than a primary level of education, which could facilitate their understanding of OS. As many of them were full-time farmers with an average of eight years of experience in organic agriculture, they were having satisfactory experiences in both farming activities and maintaining OS. The annual household income of these farmers was $43 \%$ less than the average household income of the national rural sector in $2016(58,137 \mathrm{LKR})$ (Department of Census and Statistics, Sri Lanka). Therefore, they were financially weaker than the average rural citizens of Sri Lanka. 
Table 01: $\quad$ Socioeconomic characteristics of certified organic tea farmers $(n=77)$.

\begin{tabular}{llc}
\hline & Characteristics & Value \\
\hline Average age (Years)(SD) & Male & $55(11.1)$ \\
\hline \multirow{2}{*}{ Gender } & Female & $50.6 \%$ \\
& Primary & $49.4 \%$ \\
\hline \multirow{2}{*}{ Education level } & G.C.E.OL & $24.7 \%$ \\
& G.C.E.AL & $44.2 \%$ \\
& Other & $28.6 \%$ \\
\multirow{2}{*}{ Farming type } & Full time & $2.6 \%$ \\
\hline Average experience in organic agriculture (Years)(SD) & $67.5 \%$ \\
\hline Average monthly household income (LKR)(SD) & $32.5 \%$ \\
\hline
\end{tabular}

Note: LKR=Sri Lankan Rupees $(1 U S D=153.65 \mathrm{LKR})$

\section{The characteristics of COT farms}

The characteristics of COT farms are summarized in Table 02. According to that, these farms were small in extent (Mean=0.91Acre) and observed as a distinctive portion of the farmer's home garden. Many farms were under mono-cropping systems, and their plant diversity was low. Apart from tea bushes, farms under both mono and mixed cropping systems had shade trees \{e.g. Gliricidia (Gliricidia sepium), Gravillea (Grevillea robusta)\}, and food crop trees (e.g., coconut, mango, jackfruit). The number of these plants was higher in mixed-cropping systems than in mono-cropping systems. The average density of tea bushes in the mono-cropping system was $12 \%-30 \%$ lower than the recommended density (40005000 bushes/acre) for conventional farms. In mixed-cropping systems, it was 30\% lower than the mono-cropping systems.

Farms were less prone to contaminate from irrigation, as rainwater was the primary irrigation source. However, if a farm is beneath a conventional farm, water that runs over can bring harmful contaminants. Many farmers avoid using insecticides, fungicides, and weedicides in their farms. Some farmers have used approved methods such as cultural methods (pruning plant parts, cleaning bushes, shade management) and application of Bordeaux mixture/Bordo Mix. (A mixture of Copper (II) Sulphate $\left(\mathrm{CuSO}_{4}\right)$ and slaked lime $\left(\mathrm{Ca}(\mathrm{OH})_{2}\right)$ as a fungicide. Many farmers suppress weed growth by using mechanical methods such as hand, bush-cutter, and hoe. In field-observations, it was identified that weeding by hoes increases soil erosion in sloping lands.

Farmers used different fertilizer sources, that is, homemade compost and green manure, farm manure and commercial organic fertilizers. The commercial organic fertilizers were approved by third-party certification agencies to use in organic farms, and they were supplied to the farm-gate by certificate holders. Farmers reported that live fence around the farm provides green manure while their own fertilizer preparations (compost pits, piles and liquid fertilizers units, Vermiwash, and biodynamic preparations) provide homemade composts. The presence of livestock (e.g., cattle or poultry) in owned or nearby farms (neighbours, commercial) facilitated obtaining farm manure.

Many farmers used family labour than hired or shared labour as it was safer and convenient for them in COT farming. The average yield of farms under the mono-cropping system was nearly $40 \%$ lower than the national average of conventional farms $(\approx 4200 \mathrm{~kg} / \mathrm{acre} /$ year) (Tea Small Holdings Development Authority, 2015). In mixed-cropping systems, it was nearly $53 \%$ lower than the mono-cropping systems. Although there were village collectors who bought conventional tea leaves and transported them to the processing factories, many farmers sold their produce to their certificate holders as their price margin for the unit product was around $11 \%$ higher than the conventional buyers. 
Table 02: $\quad$ Characteristics of certified organic tea farms $(n=77)$

\begin{tabular}{|c|c|c|}
\hline \multicolumn{2}{|c|}{ Characteristics } & Value \\
\hline \multicolumn{2}{|l|}{ Average farm extent (acres)(SD) } & $0.91(0.95)$ \\
\hline \multirow{2}{*}{ Cropping system } & Mono-cropping & $68.8 \%$ \\
\hline & Mixed cropping & $31.2 \%$ \\
\hline \multirow{2}{*}{ Average tea plant densities (bushes/acre) (SD) } & Mono-cropping & $3507.45(1726.92)$ \\
\hline & Mixed cropping & $2456.35(1414.32)$ \\
\hline \multirow{2}{*}{ Irrigation } & Rainfed & $100.0 \%$ \\
\hline & Irrigated & $0.0 \%$ \\
\hline \multirow{3}{*}{ Insect controlling method } & Synthetic & $1.3 \%$ \\
\hline & Approved & $29.9 \%$ \\
\hline & None & $68.8 \%$ \\
\hline \multirow{3}{*}{ Fungi controlling method } & Synthetic & $0.0 \%$ \\
\hline & Approved & $31.2 \%$ \\
\hline & None & $68.8 \%$ \\
\hline \multirow{3}{*}{ Weed controlling method } & Synthetic & $0.0 \%$ \\
\hline & Mechanical & $98.7 \%$ \\
\hline & None & $1.3 \%$ \\
\hline \multirow{5}{*}{ Fertilizer source } & Synthetic & $0.0 \%$ \\
\hline & Homemade compost \& green manure & $33.8 \%$ \\
\hline & Farm manure & $24.7 \%$ \\
\hline & Commercial organic & $35.1 \%$ \\
\hline & None & $6.5 \%$ \\
\hline \multirow{3}{*}{ Labour use } & Family & $70.1 \%$ \\
\hline & Hired & $28.6 \%$ \\
\hline & Shared & $1.3 \%$ \\
\hline \multirow{2}{*}{ Average annual harvest (kg/acre) (SD) } & Mono-cropping systems & $1877.05(1378.86)$ \\
\hline & Mixed cropping systems & $888.46(622.65)$ \\
\hline \multirow{2}{*}{ Marketing channel } & Certificate holder & $97.4 \%$ \\
\hline & Conventional tea leaf collector & $2.6 \%$ \\
\hline \multirow{2}{*}{ Average selling price (LKR/kg) (SD) } & Certificate holder & $87.53(11.13)$ \\
\hline & Conventional tea leaf collector & 79 \\
\hline
\end{tabular}

\section{Reason to select COT farming}

Although the yield is lower in organic food production systems, its combination with input cost reduction and higher price premiums results in a net profit (Qiao et al., 2016). When organic farming is associated with Fairtrade certification, it provides many services to improve the living standards of farmers (Qiao et al., 2016). According to Table 03, farmers had different reasons for selecting COT farming. The popular reasons were profits and benefits from both the certificate holder and farmer organization. Certificate holders mentioned that they have Fairtrade certifications for their products, and they use Fairtrade premiums to provide services to improve farm output and farmers' living standards. The farmers cited that they received training, farm tools, planting materials, approved organic fertilizers, and approved pesticides from certificate holders to improve production, as well as purchasing and transportation services to facilitate the marketing of their produce.

\section{Perceived deterrence by quality assurance systems}

According to Table 04, farmers "slightly agreed" that the OS were fair. Farmers have been warned by the certificate holders about the consequences of violating the OS (loss of membership). Also, the farms were regularly inspected by field inspectors of the internal control system. These field inspectors visit a farmer at least once a month. Annually, the 
third-party certification bodies also inspect a representative sample of the farmers. According to farmers' views, purchasing and extension officers also occasionally visit farmers. However, discussions with farmers revealed that many of them are unable to distinguish the officials' differing purposes in their visits.

Farmers sometimes engage in furtive behaviours to mislead the auditing system and to falsely indicate that their products are compliant with OS (Hatanaka, 2010). In this study, a group of inspectors from a third-party certification agency reported that they had witnessed such behaviours among tea farmers as storing pesticides and synthetic fertilizers in unnoticeable locations (E.g., rooftops, woodsheds, and toilets). Farmers "moderately agreed" that non-compliances are detectable without laboratory investigations. Farmers agreed that if they are detected for violating OS, they will have sure, prompt and severe consequences. Farmers reported that losing membership is a severe loss because they will lose all the financial and non-financial benefits. They also reported that they were sure about the consequences for non-compliance and the swiftness of the consequences, as they had witnessed how previous non-compliant farmers were treated.

\section{The attitude on organic agriculture}

A summary result of 15 attitudinal statements on organic agriculture is provided in Table 05. Among them, farmers had a high favourable attitude toward ten statements, moderately favourable attitude toward three statements and unfavourable attitude toward two statements. Farmers believed that organic agriculture is good as it improved soil fertility, biodiversity, and traditional knowledge.

Moreover, they believed that it increased the quality, demand, and price of their produce. Furthermore, they mentioned reducing the production cost by facilitating weed, fungal disease and insect control as advantages of organic agriculture. Farmers believed that organic agriculture had a moderate ability to reduce nutrient deficiencies, facilitate farm practices, and find suitable agricultural inputs. However, farmers mentioned that COT farming gave a low yield and low benefits for them compared to the consumers.

Table 03: $\quad$ Reasons to select certified organic tea farming $(n=77)$

\begin{tabular}{clc}
\hline \multicolumn{1}{c}{ Reasons } & $\%$ \\
\hline 1. & Higher profits & 48.1 \\
2. & Benefits from the certificate holder & 42.1 \\
3. & Benefits from the farmer organization & 16.9 \\
4. & Self-satisfaction & 7.8 \\
5. & Others & 6.5 \\
\hline
\end{tabular}

Table 04: Perceived deterrence by quality assurance system for non-compliances $(n=77)$

\begin{tabular}{lcc}
\hline \multicolumn{1}{c}{ Statement } & Mean & SD \\
\hline I believe these organic standards are fair for small-scale producers & 3.6 & 0.9 \\
I am aware of all the consequences of non-compliances & 4.3 & 0.6 \\
My certified organic tea farm is frequently inspected & 3.8 & 0.7 \\
I think non-compliances can be identified without laboratory analysis & 3.4 & 1.1 \\
I am certain that non-compliant producers are punished accordingly & 3.9 & 0.5 \\
I think non-compliances are promptly handled & 3.9 & 0.9 \\
For me the consequences of non-compliances are severe & 3.9 & 0.6 \\
\hline
\end{tabular}

Note (1: Highly disagree,2: Disagree,3: Undecided,4: Agree,5: Highly agree) 
Table 05: $\quad$ Attitude on organic agriculture $(n=77)$

\begin{tabular}{cllcc}
\hline Attitude & \multicolumn{2}{c}{ Statement (Compared to the conventional agriculture organic agriculture...) } & Mean & SD \\
\hline & 1. & Protects soil fertility in the long run & 4.3 & 0.5 \\
& 2. & Increases the demand of products & 4.3 & 0.7 \\
& 3. & Increases the prices of products & 4.2 & 0.8 \\
& 4. & Protects biodiversity & 4.0 & 0.6 \\
Favourable & 5. & Strengthens the traditional knowledge & 4.0 & 0.7 \\
& 6. & Reduces the cost of production & 3.9 & 0.9 \\
& 7. & Produces a high-quality produce & 3.9 & 0.7 \\
& 8. & Facilitates weed control & 3.8 & 1.1 \\
& 9. & Facilitates fungal disease control & 3.8 & 0.9 \\
& 10. & Facilitates the insect control & 3.7 & 0.9 \\
\hline \multirow{5}{*}{ Moderate } & 11. & Reduces nutrient deficiencies & 3.1 & 1.2 \\
& 12. & Simplifies farm practices & 2.9 & 1.1 \\
& 13. & Simplifies finding agricultural inputs & 2.8 & 1.1 \\
\hline \multirow{2}{*}{ Unfavourable } & 14. & Increases the yield & 1.9 & 0.9 \\
& 15. & Provides benefits for producers than consumers & 1.8 & 0.7 \\
\hline
\end{tabular}

Note (1: Highly disagree, 2: Disagree, 3: Undecided,4: Agree,5: Highly agree)

\section{Compliance towards OS}

Table 06 presents farmers' self-reported compliance towards OS that was concerned in this study. According to that, farmers were highly compliant in avoiding applying prohibited materials (i.e. synthetic weedicides, insecticides and fertilizers.). They also had a favourable compliance to avoid storing pesticides and synthetic fertilizers in the farm premises, avoid adjoining their organic farms with neighbouring conventional farms, apply only organically produced fertilizers, and avoid sharing their farm tools with conventional farmers. However, these farmers were moderately compliant in maintaining biodiversity and regular farm records.

Table 06: Compliance towards organic standards $(n=77)$

\begin{tabular}{|c|c|c|c|}
\hline & Statement & Mean & SD \\
\hline \multirow{7}{*}{ 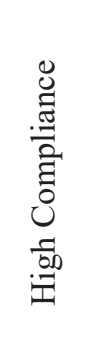 } & 1. Weedicides are not applied in the certified organic tea farm & 5.0 & 0.2 \\
\hline & 2. Insecticides are not applied in the certified organic tea farm & 5.0 & 0.1 \\
\hline & 3. Synthetic fertilizers are not applied in the certified organic tea farm & 4.9 & 0.4 \\
\hline & 4. Pesticides and synthetic fertilizers are not stored in certified organic tea farm premises & 4.3 & 1.3 \\
\hline & 5. There are no conventional farms adjoining to the certified organic tea farm & 4.1 & 1.5 \\
\hline & 6. Only organically produced fertilizers are applied in the certified organic tea farm & 3.9 & 1.4 \\
\hline & 7. Farm tools for certified organic tea farming are not shared with conventional farmers & 3.6 & 1.5 \\
\hline \multirow{4}{*}{ 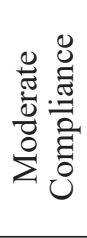 } & 8. Habitats of natural enemies of pests are protected in certified organic tea farm premises & 3.0 & 1.4 \\
\hline & 9. The certified organic tea farm is not maintained as a mono-cropping system & 2.9 & 1.6 \\
\hline & $\begin{array}{l}\text { 10. Local suitability is considered when selecting planting materials for certified organic tea } \\
\text { farming }\end{array}$ & 2.8 & 1.6 \\
\hline & 11. All the activities of certified organic tea farming are documented & 2.7 & 1.4 \\
\hline \multirow{4}{*}{ 范 } & 12. Chemically treated planting materials are not used for certified organic tea farming & 2.2 & 1.5 \\
\hline & 13. The certified organic tea farm is protected from human faecal contaminants & 1.9 & 1.4 \\
\hline & 14. The certified organic tea farm is physically separated from conventional areas & 1.7 & 1.2 \\
\hline & 15. The certified organic tea farm is protected from pesticide drifts coming from outside & 1.2 & 0.7 \\
\hline
\end{tabular}

Note (1: Highly disagree, 2: Disagree,3: Undecided,4: Agree,5: Highly agree) 
Interestingly, farmers were less compliant in avoiding chemically treated planting materials and in protecting the farm from human faecal contaminants and chemical drifts coming from outside.

\section{DISCUSSION}

Gains of compliance and losses of noncompliance in COT production

Based on the Becker's "Supply of offence", Zorn et al., (2009) have explained that the determinants of organic frauds as income of an offence, the probability that non-compliance is detected and, the penalty in case of detection and the appropriate punishment. According to those, an opportunistic individual will compare the expected utility of complying with the standard or cheating. Therefore, in the organic farming context, a farmer may select the best alternative out of which he gets a better-expected utility.

In this study, despite the low yield, the financial and non-financial benefits (Table 02 and 03) of COT farming has been able to provide a higher net return for farmers compared to conventional tea farming. Moreover, the longterm involvement in COT farming (Table 01) has improved the farmers' trust towards the certainty of those returns. Therefore, aligning with the Best (2009) it appears that the farmers have adopted COT farming due to its' higher utility than conventional tea production.

Currently, farmers are enjoying both financial and non-financial benefits of COT production and losing those is a challenge for them (Table 03). The losses of benefits are attached to noncompliances, and thereby, farmers are fear to engage in non-compliant activities. When farmers become afraid of losses arising from non-compliances, the expected loss itself discourages farmers' involvement in noncompliant behaviours (Ramcilovic-Suominen and Hansen, 2012; Ramcilovic-Suominen and Epstein, 2015). This expected loss is a multiplication of severity and the frequency of loss (Expected Loss=Loss Frequency*Loss
Severity). Sanctions that are imposed on noncompliant behaviours define the severity of the loss. Gambelli et al., (2014) identified non-compliances in two primary levels: slight and severe. They explained that slight noncompliances include sanctions such as written remarks or warnings, whereas for severe non-compliances the sanctions will be batch suppression or decertification. Therefore, two distinct severities can be identified in the losses based on the sanction types.

The probability of occurring sanctions reflects the probability of detecting non-compliances. Quality assurance systems that are field inspections by internal control systems and third-party certification agencies identify non-compliances and possible risks for COT farms (E.g., adjoined conventional farmlands). Frequent inspections increase the probability of detecting non-compliances and thereby increase the probability of sanctions. Although there are occasions for farmers to sneak around the inspection and auditing systems (Hatanaka, 2010), continuous inspection field visits by an experienced inspector can easily detect noncompliance, even the unnoticeable ones (E.g., hidden pesticides and fertilizer storages). In this study, officials of the quality assurance systems continuously inspect farmers and their farms. Therefore, if farmers are non-compliant, their perceived probability that a sanction to occur will be high. Also, frequent notifications about the non-compliances and their associated consequences increase the farmers' expected loss.

When people have higher benefits from something, they have a positive attitude toward it (Chen and Li, 2007; Lee, 2009; Hartmann and Apaolaza-Ibáñez, 2012). As farmers receive benefits from COT farming, they also may have a favourable attitude towards organic agriculture. As attitude has been recognized as a fundamental component of compliance behaviour by many studies (Mweemba et al., 2008; Darawad and Al-Hussami, 2013), the gains of COT farming will positively affect on the attitude and then to the compliance behaviour. 


\section{Complying with OS in COT production}

High compliances, In COT production, contaminating a farm with pesticides and synthetic fertilizers often leads to decertify non-compliant farmers. As Gambelli et al., (2014) explained, these are considered as severe non-compliances in organic farming. Quality assurance systems also put great attention to avoid these pesticides and fertilizers in organic farms. Thus, they have a high probability of detection. Concerning the explanation by Zorn et al., (2009), the presence of pesticides of synthetic fertilizers decreases the expected utility that farmers can get from COT production. Non-compliance in those aspects has no better gain either. Therefore, as farmers have perceived that the expected loss of decertification is more significant than gain of being non-compliant, they tend to avoid applying and storing pesticides (weedicide and insecticides) and synthetic fertilizer in their farm premises.

A study by Scalco et al., (2017) found that organic producers' permanence in certified activities is uncertain if they have difficulties in meeting the requirement of organic farming. They recommend improving the capacities of service providers such as extension agents to assist and guide organic producers to meet the requirement of organic farming. In this study, it has been found that certificate holders have provided bush cutters/sling blades for farmers to control weeds easier. Moreover, an approved fungicide (Bordeaux mixture) or ingredients \{Copper (II) Sulphate (CuSO4) and slaked lime $(\mathrm{Ca}(\mathrm{OH}) 2)\}$ to produce, it has been provided to control Blister blight disease. Therefore, these supports have facilitated farmers to avoid harmful agrochemicals from their organic farms.

Similarly, these farmers found to be regularly trained about organic fertilizer preparation, and sometimes they have been provided with an organic fertilizer at a low price by certificate holders. Therefore, such assistance and guidances have led farmers to avoid synthetic fertilizer, and at the same time, to add organic fertilizer.

However, some farmers have added farm manure (E.g., poultry manure from commercial farms) to their COT farms as organic fertilizers. Farm manure is discouraged from using in organic farming unless a third-party certification permits it because farm manure can be contaminated with hormones, pathogens, or antibiotics (International Federation of Organic Agriculture Movements, 2014). Therefore, it is essential to investigate whether farm manures available for these farmers are free from hazardous contaminants before using them in organic farms.

In organic farming, formation and functioning of groups are encouraged for small-scale producers as it facilitates market access and capacity building, and affordable organic certification (Meinshausen et al., 2019). Apart from that, if members of groups are living in the same neighbourhood, it can reduce the availability of contaminants in that area as farmers do not use harmful substances such as pesticides and synthetic fertilizers. It is apparent that if the membership of groups increases, it will minimizes the risk of organic farms to contaminate with pesticides and synthetic fertilizers. There is only one certificate of conformity for the whole group. If one member fails the compliance in the inspections, the whole group will be sanctioned (Barrett et al., 2001). Hence, the compliance of an individual farmer is critical when farmers are in groups. During field observations in this study, it has been identified that the farmers operated as groups, and often live in the same neighbourhood. Moreover, certificate holders reported that they hesitate to recruit COT farmers if conventional farms surround COT farmers' farms. Therefore, it is apparent that group farming has been the main reason for many farmers to avoid conventional farms adjoined with their COT farms.

Farmers were highly compliant not to share farm tools with conventional farmers. These farm tools include hoe, spade, sling blades, knives 
etc. Although these farming communities live in a confined area, they hardly share their farm tools. This is because perhaps that such tools are available in almost all the farm households. Therefore, farmers do not need to depend on others or others' tools for their farm activities.

\section{Moderate compliances}

Biological pest control reduces the dependency on pesticides in organic farming. If farmers can protect and create habitats for natural enemies of pests, it will provide suitable ecological infrastructure with resources (E.g., food for adult natural enemies and alternative prey or hosts) for their existence in the farm (Landis et al., 2000). If farmers manage proper plant diversity, they can effectively control the impact of pest and diseases (Ratnadass et al., 2012). Belfrage et al., (2006) found that small-scale organic farms are having better biodiversity as those lands have a lack of pesticides, crop rotation, high grazing intensity, heterogeneous landscapes with higher crop species diversity. In this study, the compliance with maintaining habitats of natural enemies of pests and a variety of crops is mainly because COT farms are small in scale and they are part of farmers'home gardens. In these small home gardens, farmers establish different plants (E.g., Fruits, timber, medicinal, food crops, ornamental plants, etc.) that useful for their household consumption. Therefore, the surrounding of COT farms appears as rich in biodiversity while facilitating the existence of natural enemies of pests.

However, it has also been found that willful maintenance of biodiversity is absent in the farms. Hence, if farmers are unaware of maintaining biodiversity as a fundamental requirement in an organic farm, they may not make an extra effort to maintain it. Scalco et al., (2017) mentioned that, if farmers lack information about the requirements in organic production, including biodiversity management, it will be a challenge for them to comply with those requirements. Therefore, though farmers are compliant in some areas, proper investigation is necessary to recognize whether those compliances are intentional or unintentional to take necessary actions to make the compliance sustainable.

Farmers receive planting materials from their nurseries, neighbouring nurseries or certificate holders. Some of these plant nurseries are financially assisted and inspected for the suitability by certificate holders. However, these nurseries or supplies cannot afford the plant demands of all the farmers. In such cases, farmers depend on any available plant nursery in their areas. When plants are well grown in the locality, farmers may have perceived that they are suitable for their organic farms. Moreover, according to the farmers' views, there are no specific sanctions for not selecting suitable planting materials. Therefore, this is perhaps the reason for them to show a moderate compliance towards selecting planting materials that are perfectly suitable for their farms.

Record keeping is useful but often raised as a non-compliance in organic farming due to less practice by farmers (Meinshausen et al., 2019). In this study, all the farmers had farm record books given by certificate holders, but farmers had recorded only the basic details such as their demographic and farm characteristics rather than ongoing farm activities such as farming practices, sales, and marketing. Farmers reported that despite officers of certificate holders sign the farm record book during their field visits and advise them to record ongoing farm activities, they have never used the records for their farm-related decision making. Moreover, they mentioned that they have never been punished for not maintaining them. Record-keeping is solely a requirement in the certification process and certification bodies often rely on records at the group or sub-group level rather individual level (Meinshausen et al., 2019). Therefore, if internal control systems maintain necessary records for certification process at the group or sub-group level, they may not pay attention to the record maintenance by farmers.

\section{Low compliance}

Finding chemical-free planting materials is essential in COT production. Farmers can 
produce the required amount of planting material for their COT farms if they have suitable propagating materials, time, money and technical know-how. Otherwise, there should be commercial nurseries for farmers to purchase suitable planting materials for their COT farms. Since many farmers used tea plants from conventional nurseries, in this study, it can be assumed that many COT farmers have not attempted to have plant nurseries for their own or there are no suitable commercial plant nurseries in their localities. Although few farmers have received planting materials from their coordinators, it seems that those coordinators have less capacity to afford the total demand of their member farmers. Therefore, the reasons behind farmers' incapability to produce required planting materials should be investigated to provide suitable support services and then to increase their compliance with planting material related OS.

Tiryaki (2017) reported that the residues in organic products not only because of intentional uses but also could be due to other causes such as undefined causes, contamination without farmer's knowledge, inadequate care, mix-up of organic and conventional foods. He further reported that many residues found in many organic products are related to the persistent organic pollutants from agroecosystems. Therefore, farmers have to be very careful in recognizing potential threats for their organic farms and products from outsides and implement necessary action to minimize their impacts.

Physically separating COT farms from conventional areas continuously and entirely is required to minimize the potential threats coming from outsides such as pesticide drifts and runoff water contaminated with possible hazardous compounds. Although establishing barriers such as walls, stone fences etc. could minimize abovementioned threats, those structures need a high amount of investment which poor farmers are incapable of contributing. In this study, farmers have not separated their COT farm area in a way that would exclude contaminants coming from outside the farm area and domestic environments such as household wastes and human or animal faecal matters (E.g., if people urinate near COT farm). Perhaps these farmers' less financial capacity has hindered them establishing barriers around their farms or else farmers are unaware of how their COT farms can be contaminated from outside sources and domestic wastes.

Farmers and quality assurance systems frequently focus their attention on farming practices rather than post-harvest handling practices. This makes them blind to the severity that exists in the post-harvest handling practices. In the study, it has been found that some farmers harvested their produce in empty fertilizer bags and process the harvest (collect and re-bag) on areas which are vulnerable to contamination from human faecal matter and household wastes (E.g., pavements, cemented floors of the house). After re-bagging, they keep their fresh tea leaf bags on the racks near roadsides. As these racks were not appropriately covered, they created an environment vulnerable to contamination with pollutants from the surrounding areas, including animal faecal matter. Therefore, unless farmers are aware of the risk of such handling practices, and unless they are given the facilities to avoid them, they will be less compliant in maintaining the safety of the COT produces. Furthermore, if quality assurance systems are unable to detect such risk behaviours, farmers may not perceive a high probability of occurring consequences for such behaviours.

\section{CONCLUSIONS}

This study investigated farmers' compliance behaviour towards OS when they produce certified organic tea (COT) in Sri Lanka. A cross-sectional field survey was conducted using both qualitative and qualitative research methods. Farmers selected COT farming as they perceived higher net returns, that is, financial and non-financial, benefits from it. They also had a favourable attitude towards organic agriculture, due to the many benefits associated with it besides the low yield and 
challenging farm practices. In this study, COT farmers perceive high discouragement against violating the OS and have mixed attitudes on different aspects of organic farming.

Farmers are not perfectly compliant with all the OS that considered. Farmers show higher compliance toward OS if there are higher expected losses for non-complaints (E.g., applying and storing agrochemicals in the farm). If there are less expected losses or gains, difficulties of finding substitute organic inputs, lack of financial capacity and unawareness of possible risks, farmers tend to have moderate or less compliance (E.g., maintaining farm records). Effective quality assurance system and hazardous free neighbourhood facilitate the compliance of COT farmers. However, the lack of perfect substitutes or suitable supportive services (E.g., organically produce fertilizers, training and extension services) hinders farmers' compliance with the OS. Also, if farmers have less capacity to design their farms to defend outside risk factors (E.g., household wasters, pesticide drifts), it will be a challenge for them to fully comply with some of the OS. Finally, unawareness of risks not only in and around the farming area but in post-harvest handling may blind their loss calculation while leaving their products vulnerable to contamination with those risk factors.

As for the main implications, this study suggests increasing the farmers' benefits for complying with different OS, that would increase their compliance behaviour. Moreover, it will also increase their expected loss if they become non-compliant with different OS by imposing sanctions. Moreover, facilitating the production of organic inputs (E.g., producing nurseries and fertilizer units) by farmer groups will facilitate both group interactions and organic farming practices. Lastly, educating farmers and quality assurance officers about the risk factors in postharvest handling would be helpful for them to make COT more safely and then to establish sustainable, trustworthy COT farming systems.

\section{Data availability statement}

The datasets generated during and/or analysed during the current study are available from the corresponding author on a reasonable request.

\section{ACKNOWLEDGEMENT}

The authors acknowledge the valuable support provided by the coordinating organizations and the small-scale organic tea farmers throughout the study period.

\section{REFERENCES}

Arias, A. (2015). "Understanding and managing compliance in the nature conservation context", Journal of environmental management, 153, pp.134-143.

Barrett, H.R., Browne, A.W., Harris, P.J.C. and Cadoret, K. (2001) "Smallholder Farmers and Organic Certification. Accessing the EU Market from the Developing World", Biological Agriculture \& Horticulture, 19 (2), 183-199.DOI:10.1080/01448765.2001.9754920.

Becker, M. H., and Maiman, L. A. (1975). "Sociobehavioral determinants of compliance with health and medical care recommendations." Medical care,13 (1), pp.10-24.

Belfrage, K., Björklund, J. and Salomonsson, L. (2005). "The effects of farm size and organic farming on diversity of birds, pollinators, and plants in a Swedish landscape". Ambio 34 (8), pp. $582-588$

Best, H. (2009). “Organic Farming as a Rational Choice”, Rationality and Society, 21(2), 197-224. DOI:10.1177/1043463109103899. 
Bosworth, M. (2005). Encyclopedia of prisons \& correctional facilities, Sage Publications, Thousand Oaks, Calif., London.

Brannen, J. (2005). "Mixing Methods: The Entry of Qualitative and Quantitative Approaches into the Research Process", International Journal of Social Research Methodology, 8 (3),173184. DOI:10.1080/13645570500154642.

Campbell, A. (2015) "Popular natural and organic tea companies violate pesticide laws" https:// www.naturalhealth365.com/organic-tea-pesticides-1630.html.25.04.2018.

Chen, M.-F. and Li, H.-L. (2007) "The consumer's attitude toward genetically modified foods in Taiwan", Food Quality and Preference, 18 (4), 662-674. DOI: 10.1016/j. foodqual.2006.10.002.

Cialdini, R.B. and Goldstein, N.J. (2004). "Social influence: compliance and conformity", Annual review of psychology, 55, pp. 591-621.

Cressey, P., Vannoort, R. and Malcolm, C. (2009). Pesticide residues in conventionally grown and organic New Zealand produce food additives \& contaminants. Part B, Surveillance 2(1), 21-26. DOI:10.1080/02652030802684096.

Darawad, M.W. and Al-Hussami, M. (2013). “Jordanian nursing students' knowledge of, attitudes towards, and compliance with infection control precautions", Nurse education today, 33(6), 580-583. DOI: 10.1016/j.nedt.2012.06.009.

Department of Census and Statistics, Sri Lanka (2015). "Household Income and Expenditure. Survey-2012/13. Final Report”. Department of Census and Statistics Sri Lanka. Battaramulla. http://www.statistics.gov.lk/HIES/HIES2012_13FinalReport.pdf.04.03.2018

Deutsch, M and Harold B. G, (1955). "A study of normative and informational social influences upon individual judgment." The Journal of Abnormal and Social Psychology, 51 (3): 62936. DOI:10.1037/h0046408.

Dias, S. (2018). "Business Times: RPCs teas to be tested from next week." http://www.sundaytimes. lk/180211/business-times/rpcs-teas-to-be-tested-from-next-week-281437.html.04.03. 2018

Gambelli, D. Solfanelli, F and Zanoli, F. (2011). "Noncompliance in organic certification: determinants for Italy." Organic is Life-Knowledge for tomorrow, In: Neuhoff, Daniel; Halberg, Niels; Rasmussen, Ilse A.; Hermansen, J.E.; Ssekyewa, Charles and Sohn, Sang Mok (Eds.) Organic is Life - Knowledge for tomorrow, II, pp. 112-115.

Gambelli, D., Solfanelli, F., Zanoli, R., Zorn, A., Lippert, C. and Dabbert, S. (2014). "Noncompliance in organic farming. A cross-country comparison of Italy and Germany", Food Policy, 49, pp. 449-458.

Gunarathne, L.H.P. (2015). "Comparative Efficiency of Organic and Conventional Tea and Its Rural Development Implications in Sri Lanka", in Markandya, A. and Setboonsarng, S. (Eds.), Organic Agriculture and Post-2015 Development Goals: Building on the Comparative Advantage of Poor Farmers, Asian Development Bank, pp. 279-290.https://think-asia.org/ handle/11540/4411. 04.04.2018. 
Hartmann, P. and Apaolaza-Ibáñez, V. (2012). "Consumer attitude and purchase intention toward green energy brands: The roles of psychological benefits and environmental concern", Journal of Business Research, 65 (9), 1254-1263. DOI: 10.1016/j.jbusres.2011.11.001.

Hatanaka, M. (2010). "Governing sustainability. Examining audits and compliance in a thirdparty-certified organic shrimp farming project in rural Indonesia”, Local Environment, 15 (3),233-244. DOI:10.1080/13549830903575588.

Herzfeld, T and Jongeneel, R. (2012). "Why do farmers behave as they do? Understanding compliance with rural, agricultural, and food attribute standards." Land Use Policy, 29 (1): 250-60. DOI: 10.1016/j.landusepol.2011.06.014.

Hsu, SY., Chang, CC. and T. Lin, T. (2016). "An analysis of purchase intentions toward organic food on health consciousness and food safety with/under structural equation modelling”, British Food Journal, 118, (1), 200-216.DOI:10.1108/BFJ-11-2014-0376

International Federation of Organic Agriculture Movements. (2014). The IFOAM NORMS for Organic Production and Processing: Version 2014, Germany. https://www.ifoam.bio/.

Keen, P. (2018). "Pesticides in tea: Getting a clear picture not a vague impression." https:// teajourney.pub/pesticides-tea-getting-clear-picture-not-vague-impression/. 25.04.2018.

Kelman, H.C. (1958). "Compliance, identification, and internalization three processes of attitude change." Journal of Conflict Resolution 2 (1), 51-60. DOI:10.1177/002200275800200106.

Kyngäs, H., Duffy, M. E. and Kroll.T. (2000). “Conceptual analysis of compliance.” Journal of clinical nursing 9 (1), pp.5-12.

Landis, D. A., Wratten, S. D. and Gurr, G. M. (2000). "Habitat management to conserve natural enemies of arthropod pests in agriculture." Annual review of entomology, 45, pp.175-201.

Latane, B. (1981). "The psychology of social impact." American Psychologist, 36 (4), 343-56. DOI:10.1037/0003-066X.36.4.343.

Lee, M-C. (2009). "Factors influencing the adoption of internet banking: An integration of TAM and TPB with perceived risk and perceived benefit." Electronic Commerce Research and Applications, 8 (3), 130-41.DOI: 10.1016/j.elerap.2008.11.006.

Lei, L. (2017). "Effects of standards on tea exports from developing countries: comparison of China and Sri Lanka." IDE Discussion Papers (642). https://ideas.repec.org/p/jet/dpaper/ dpaper642.html. 04.03.2018.

Lippert, C., Zorn, A. and Dabbert, S. (2014). "Econometric analysis of noncompliance with organic farming standards in Switzerland." Agricultural Economics, 45 (3), 313-25. DOI:10.1111/ agec. 12067 .

Martín, A.M., Hernández, B., Martha, F-A. and Hess, S. (2014). "Why ordinary people comply with environmental laws: A structural model on normative and attitudinal determinants of illegal anti-ecological behaviour." Leg Crim Psychol, 19 (1), 80-103. DOI:10.1111 /j.2044-8333.2012.02062. x. 
Meinshausen, F., Richter, T., Blockheel, J. and Huber, B. (2019). "Group Certification. Internal Control Systems in Organic Agriculture: Significance, Opportunities and Challenges". Research Institute of Organic Agriculture FiBL. http://orgprints.org/35159/. 07.18.2019.

Muriithi, B.W., Mburu, J. and Ngigi, M. (2011). "Constraints and determinants of compliance with EurepGap standards: A case of smallholder French bean exporters in Kirinyaga district, Kenya." Agribusiness, 27 (2),193-204. DOI:10.1002/agr.20261.

Mweemba, P., Haruzivishe C., Seter Siziya, P.J., Chipimo, K. Cristenson, and Johansson, E. (2008). "Knowledge, attitude and compliance with tuberculosis treatment, Lusaka, Zambia." 0047651X. https://bora.uib.no/bitstream/1956/3476/1/TBcomplaincePMPJ.pdf.19.5.2019

Qiao, Y., Halberg, N., Vaheesan, S. and Scott, S. (2016). “Assessing the social and economic benefits of organic and fair trade tea production for small-scale farmers in Asia: a comparative case study of China and Sri Lanka." Renewable Agriculture and Food Systems, 31 (03): 246-57. DOI:10.1017/S1742170515000162.

Ramcilovic-Suominen, S. and Epstein, G. (2015). "The impacts of deterrence, social norms and legitimacy on forest rule compliance in Ghana." Forest Policy and Economics, 55, 10-20. DOI: $10.1016 /$ j.forpol.2015.03.006

Ramcilovic-Suominen, S. and Hansen, C.P. (2012). "Why some forest rules are obeyed and others violated by farmers in Ghana: Instrumental and normative perspective of forest law compliance." Forest Policy and Economics 23:46-54. DOI: 10.1016/j.forpol.2012.07.002

Ratnadass, A., Fernandes, P., Avelino, J. and Habib, R. (2012). "Plant species diversity for sustainable management of crop pests and diseases in agroecosystems: a review", Agronomy for Sustainable Development, 32 (1), 273-303.DOI:10.1007/s13593-011-0022-4.

Simpson, P.V. (2009). "Pesticides found in organic tea." https://www.thelocal.se/20091105/23086, 25.04.2018.

Sinnasamy, P., Bidin, Z. and Ismail, S.S.S. (2015). "A Proposed Model of Non-compliance Behaviour on Excise Duty: A Moderating Effects of Tax Agents." Procedia - Social and Behavioral Sciences, 211, pp. 299-305.

Scalco, A., Oliveira, S., Pigatto, G. and Santini, C. J. (2017). "Factors that May Lead on the Nonrenewal of Certified Organic Product According to Organic Producers in Brazil". Rev. Econ. Sociol. Rural 55 (3), pp. 465-478. DOI: 10.1590/1234-56781806-94790550303

Sutinen, Jon G., and Kuperan, K. (1999). “A socio-economic theory of regulatory compliance.” Int J of Social Economics, 26 (1/2/3),174-93, DOI:10.1108/03068299910229569.

Tea Small Holdings Development Authority. (2015). “ANNUAL REPORT 2014.” http://www. tshda.gov.lk/web/images/pdf/annual\%20report\%202014\%20english.pdf. 01.02.2015.

The Local. (2017). "Tea bags sold in France found to contain up to 17 types of pesticides." https://www.thelocal.fr/20171108/tea-bags-sold-in-france-contain-up-to-17-types-ofpesticides.25.04.2018.

Tiryaki, O. (2017). Pesticide Residues and Organic Production, Journal of Biological Environment Science, 11, pp.11-23. 
Tyler, T.R. (2006). Why people obey the law, Princeton University Press, Princeton, NJ

Vidanapathirana, R. and Wijesooriya, N. (2014), Export Market for Organic Food: Present Status, Constraints and Future Scope, Hector Kobbekaduwa Agrarian Research and Training Institute, Colombo.

Zanoli, R., Gambelli, D. and Bruschi, V. (2012). "Analysis of non-compliances in the organic certification system in Turkey.” New Medit, 11 (4), pp.74-77.

Zorn, A.,Lippert, C. and Dabbert, S. (2009). “Economic Concepts of Organic Certification”. http:// orgprints.org/16041/.07.18.2019.

Zorn, A., Lippert, C. and Dabbert, S. (2013), “An analysis of the risks of non-compliance with the European organic standard. A categorical analysis of farm data from a German control body", Food Control, Vol. 30 No. 2, pp. 692-699.DOI: 10.1016/j.foodcont.2012.08.020. 